STRATEGIC PERSPECTIVES



\title{
TRANSPORT LOGISTICS: REDEFINING LOGISTICS IN TRANSPORT
}

\section{A S Kumarage}

Department of Transport and Logistics Management, University of Moratuwa, Moratuwa, Sri Lanka

Correspondence should be addressed to amalk@uom.lk

\begin{abstract}
The terms Transport and Logistics have historically been used independently of one another. While the meaning of transport relates to the critical function of providing mobility, the understanding of logistics varies sharply between its different application contexts, from Military Logistics in early stages to its current application in Supply Chains referred to as Business Logistics. Logistics is generally understood as the processes associated with handling goods within a supply chain from its raw material supply to production to consumption, including its Transport during the multiple segments of the journey. Transport research also treats Logistics as those activities that support consuming transport itself as a means of satisfying mobility requirements but again mainly confined to the movement of goods. The recent emergence of 'Transport \& Logistics' in academia and research further confuses the scientific study of mobility issues. However, this understanding is less obfuscating in industry, as each employs it in its specific context and understands it differently.

This paper proposes the term Transport Logistics to identify the logistics associated with the different forms of transport provision. The etymology of terms Transport and Logistics have been consulted in its deduction. The paper concludes that passenger transport and goods transport have similar logistics activities to understand them as a single field of study. Moreover, the paper asserts that Logistics is a well-defined rational and logical process that can solve a difficult or complex transport problem.
\end{abstract}

Keywords: Transport Logistics, Supply Chain, Passenger, Goods, Complex Problems 


\section{DIFFERENT MEANINGS OF TRANSPORT}

Transport is used as a verb to describe the physical movement of persons or goods between two different locations. Dictionaries define Transport meaning 'to transfer or convey from one place to the other' [1] as illustrated by its use in 'Admiral da Gama, unable to leave the Bay of Rio de Janeiro on account of lack of transport for the sick and wounded and the civilians claiming his protection, could do no more than wait for Admiral Mello to return from Desterro' [2]. As a verb, it refers to the function of being carried or taken, which is identified as the 'demand' side of mobility, represents the user's utility or requirement. The term Transport can also be used as a noun as illustrated in 'the client will provide the required transport', referring to it as a means of satisfying the desire for mobility, representing its supply side.

The English word 'transport' we are discussing is derived from the Latin words 'trans' meaning 'across' and 'portare' meaning to carry; when combined, made up the word 'transportare', which, adapted initially as 'transporter' in the old French, was translated into English around 1690 [3] as 'transport'. Even though this definition aligns better with the supply side of mobility, as explained above, its everyday use refers to both the demand and supply sides of mobility. The word Transportation, of more recent American origin, further defines the supply side of transport as a 'system for carrying people or goods from one place to another using vehicle, and related infrastructure'[4], illustrated in 'the rising transportation cost was a matter of concern' or 'the transportation system needs to be modernised'.

\section{LOGISTICS AS A PROCESS OF OVERCOMING COMPLEX OPERATIONAL PROBLEMS}

The Oxford Dictionary defines Logistics as the detailed organisation and implementation of a complex operation' [5], following the understanding of the Latin word 'Logos', as the use of reasoning and logic. Logistics can therefore be understood as a supply-side function that facilitates a difficult or complex operational issue. Logistic is defined as the 'art of arithmetical calculation' dating from the 1650s [6]. It is derived from the Greek word 'Logisikos', translated to English as Logistic [7]. The more recent adoption of the term logistic in statistics includes logistic modelling (also called logit modelling) or logistic regression. It is used as a statistical technique to estimate the probability of an outcome of a decision, or an event known to be dependent on many identifiable independent conditions on which such outcome depends.

Thus, in this paper, the term Logistics will mean applying reason and logic in deriving solutions to complex problems of providing for the mobility of goods and people. 
The first recorded application of Logistics as a rational approach or science in goods transport was AN Tolstoi's work in 1930 titled 'the methods of finding the minimal total kilometrage in cargo-transportation planning in space' being an effort to solve the complex problem of optimising the movement of salt, cement, and other cargo between some 10 origins and 68 destinations on the Soviet railway network [8]. The first application of Logistics in passenger transport is recorded from the $17^{\text {th }}$ century when the French mathematician Blaise Pascal successfully designed and implemented the world's first bus network, called the Five Penny Carriages in Paris, in 1662 [9]. Though the carriages were drawn by horse and could only carry eight passengers, it had all the complexity of a modern transport network that eventually expanded to five routes with frequencies every seven or eight minutes, an affordable fare regime and even demand-based late evening services. Since then, mathematics, especially Operations Research, modelling and simulation, have been used to tackle a vast array of complex problems in transporting goods and passengers across unimodal and multimodal transport networks.

This paper defines this application of Logistics in Transport as 'Transport Logistics' However, since Logistics has well-defined meanings in other sectors, this definition must be set apart from its other applications and its common everyday use as 'making suitable arrangements' or 'handling the details of an activity'.

\section{LOGISTICS IN MILITARY PROCESSES}

It has been noted that while the word 'Logic' was derived directly from the Greek word 'Logos' meaning reason, the word Logistics though initially stemming from the same concept of reason, was a translation from the French word 'Logistique', found to have been used by Baron de Jomini in 1830 [10] as 'Logis' or arrangement of lodging of troops. From its earliest use in military functions, the term is defined as 'the aspect of military science dealing with the procurement, maintenance, and transportation of military matériel, facilities, and personnel [11]. Military logistics refers to this long-established practice of handling men and material required for war and military engagement by moving resources to specific places when and where needed. This definition of military logistics interestingly includes the movement of material and military personnel [12].

\section{LOGISTICS IN SUPPLY CHAIN PROCESSES}

In non-military use, the term Logistics is mainly associated with the supply chain processes and handling goods and not people. The Council of Supply Chain Management Professionals (CSCMP) defines a supply chain as the 'planning and management of all activities involved in sourcing and procurement, conversion, and 
all logistics management activities' [13], where Logistics is defined as an integral function within supply chains. The CSCMP [14] also defines Logistics as the 'process of planning, implementing, and controlling procedures for the efficient and effective transportation and storage of goods, including services and related information from the point of origin to the point conforming customer requirements. It clarifies that Logistics in supply chains requires the integration of a sequence of activities in the processes required to produce and distribute the material.

Peter Drucker, who defined Logistics as 'the last frontier of economics' [15], foretold Logistics taking centre stage of business. The International Society of Logistics (SOLE) has a broader definition of Logistics, giving it as 'the art and science of management, engineering, and technical activities concerned with requirements, designs and supplying and maintaining resources to support objectives, plans and operations [16]. It aligns with the current scope of Logistics within supply chain management. It has moved from being understood as integrating the internal processes in an organisation to a strategy that includes the planning, design, operation and management of the entire supply chain from producer to consumer.

Logistics is currently considered any supporting activity that enhances the value of the supply of a product or service to the end consumer. In this respect, the application of Logistics has expanded from manufacturing to service industries such as healthcare and hospitality. Key activities in Logistics within a supply chain are commonly identified as order processing, materials handling, warehousing, inventory control, transport, and packaging. In transport, the sub-activities are usually identified as modes of transport, freight consolidation, vehicle routing, delivery scheduling, equipment selection, rate setting and claims processing. These are supply-side activities for a consumer and are often called Logistics for Business, a subset of activities within the supply chain that involves the movement and storage of material [17], sometimes called Business Logistics [18]. However, most businesses require handling both material and people, namely employees and customers, to be moved from place to place. Nevertheless, academia and research in supply chain management have mostly considered material handling issues rather than people movement.

\section{GAPS AND OVERLAPS BETWEEN TRANSPORT \& LOGISTICS}

The objective of this paper is not an etymological discourse on the derivation of the words Transport and Logistics, but to determine their suitability and current relevance in the intersection of their combined use, particularly in academia and research. Transport and Logistics are two words used separately in academia, where Logistics is treated as a function within supply chain management, mainly relating to that of 
goods. It is generally treated separately from problems concerning the mobility of people, which is dealt with under Transport [19]. Passenger transport has traditionally been seen as a public issue, with significant economic and social implications, to which a government should lend its attention. On the other hand, goods transport is mainly treated as a commercial activity of private sector concern. However, these traditional boundaries are fast-changing with disruptive technologies such as mobility as a Service (MaaS) applications, Industry 4.0, and other IT-based innovations. Thus, the traditional boundaries between transport as the movement of people and logistics referring to an activity within the supply chain now require reset.

The marriage of the terms of Transport with Logistics was formalised at the incorporation of the Chartered Institute of Logistics and Transport (CILT) in 2001 when the Chartered Institute of Transport (CIT) merged with the Chartered Institute of Logistics (CIL) [20]. The CILT, which does not appear to have a definition of its own for the term Logistics, borrows that of GeorgiaTech given as 'that part of the supply chain process that plans, implements, and controls the efficient, effective flow and storage of goods, services, and related information from the point of origin to the point of consumption to meet customers' requirements' [21]. It is a slight modification of the CSCMP definition restricting it to goods and related services between origin and point of consumption; since the CILT perceives Logistics as for goods. Since Transport is interpreted to be without any such restriction, the word Logistics overlaps with that of Transport.

Consequently, the term 'Transport \& Logistics' or 'Logistics \& Transport' causes immense confusion in academia and the scientific study of mobility. Its understanding in the industry has been less problematic, as each sector uses it in their specific context, mainly using the term Logistics for the handling of goods, including its Transport. In contrast, the term Transport is understood to refer to the movement of people and goods, including their Transport Logistics. Therefore, this paper ventures to postulate that the term Logistics is equally applicable to support and arrange the handling of passengers as for the movement of goods.

\section{SIMILARITIES AND DIFFERENCES BETWEEN GOODS AND PASSENGER MOVEMENT}

As shown in Table 1, the mobility of passengers has near-identical activities to that of goods. They both require the planning, the infrastructure, the implements, and the controls for completing the practical mobility requirements of the customer commonly set out as the seven R's; getting the right product, in the right quantity, in the right condition, at the right place, at the right time, to the right customer and at 
the right price. When applied to passenger transport, except for the right customer, since it is the customer who is being transported, it is identical to goods transport.

Table 1: Comparison of Processes between Mobility of Goods and Passengers

\begin{tabular}{|c|c|c|}
\hline Feature & Goods Transport & Passenger Transport \\
\hline Customer & Shipper / Recipient & Passenger \\
\hline Origin & Producer of Material & Trip Generator \\
\hline Destination & Consumer of Material & Trip Attractor \\
\hline $\begin{array}{l}\text { Travel Segments / Trips } \\
\text { (examples) }\end{array}$ & $\begin{array}{l}\text { - Producer to Warehouse } \\
\text { - Warehouse to Retailer } \\
\text { - Retailer to Consumer } \\
\text { - Returns to above }\end{array}$ & $\begin{array}{l}\text { - Home to Work } \\
\text { - Home to School } \\
\text { - Home to Non-work } \\
\text { - Return of above }\end{array}$ \\
\hline Decision Making & Shipper or Consignee & Usually by Passenger \\
\hline Consolidating & $\begin{array}{l}\text { Package items travelling } \\
\text { together }\end{array}$ & $\begin{array}{l}\text { Passenger \& baggage travel } \\
\text { together }\end{array}$ \\
\hline Movement & Externally Assisted & $\begin{array}{l}\text { Self-propelled and } \\
\text { externally assisted }\end{array}$ \\
\hline $\begin{array}{l}\text { Aggregation / } \\
\text { Disaggregation }\end{array}$ & Distribution Centre & Terminal, Station or Airport \\
\hline $\begin{array}{l}\text { Departure / Arrival } \\
\text { Location }\end{array}$ & Dock or Bay & Platform or Gate \\
\hline Pre-Departure Activity & Loading & Boarding \\
\hline Vehicle of Movement & Goods Transport Vehicles & $\begin{array}{l}\text { Passenger Transport } \\
\text { Vehicles }\end{array}$ \\
\hline Infrastructure Facility & $\begin{array}{l}\text { Multimodal Transport } \\
\text { Network }\end{array}$ & $\begin{array}{l}\text { Multimodal Transport } \\
\text { Network }\end{array}$ \\
\hline Information Required by & Shipper and Consignee & Passenger \\
\hline Activity on Arrival & Unloading & Alighting \\
\hline Transfer and Storage & Dock or Warehouse & Terminal, Station or Airport \\
\hline Returns & Reverse Logistics & Unfulfilled Return Trip \\
\hline Payment & Shipper/Recipient & Passenger \\
\hline
\end{tabular}

While there are many similarities in the many activities, as shown above, there are also several critical differences that set apart goods transport from people transport:

a. In people transport, the passenger makes decisions on each of the processes in the journey, most often based on information and choices offered at each such decision point or beforehand. However, in goods, all decisions are usually made beforehand by the shipper or consignee on information provided by the different service providers. 
b. In the case of goods transport, all movements must be assisted or enabled by humans or automated. In contrast, in people transport, some activities such as boarding and alighting and even access or egress are usually unassisted, even though implements such as lifts, escalators and walkways are increasingly used to assist such movements. People also operate conveyances and drive, propel, or fly themselves while carrying others.

\section{INTERCHANGEABILITY BETWEEN GOODS AND PASSENGER TRIPS}

The other primary consideration is understanding the growing interchangeability between people transport and goods transport. For example, a person who wishes to eat pizza will have three basic options to satisfy the mobility requirements if he does not have a pizza. First, he can go to the restaurant and enjoy his pizza at leisure and with others resulting in a leisure passenger trip. He can enjoy his pizza while entertaining guests at home and by ordering the delivery of the pizza, which would result in a goods trip between the restaurant and house. Thirdly, he could travel to the restaurant and pick up the pizza himself and bring it home, which will be a shopping trip. All these achieve the same customer purpose while the passenger trips originate at home and terminate at the restaurant before returning home, and the pizza delivery does the opposite. Similarly, during COVID-19, many personal shopping trips are substituted by online deliveries where the last-mile delivery is provided by the supplier's door-to-door delivery service. The innovations in technology have significantly facilitated the interchange of personal and goods transport, while improving customer service.

Moreover, both person and goods trips usually occur across the same transport infrastructure such as roads, railways, airports and ports and the respective networks they create. Vehicles used on these networks are usually customised for passengers or goods, though often vehicles carry both passengers and goods. The same IT platforms can now provide both passenger services and carrying goods, often using a common fleet of vehicles. Though urban logistics is referred to as the study of the movement of goods in cities, and urban transport refers to studies the movement of passengers, the foremost issues of urban congestion and the challenge of urban planning now require the combined study and analysis of both these as city centres once congested with passenger vehicles, are increasingly congested with delivery vehicles.

Therefore, the proposed term Transport Logistics includes the role of Logistics in both people and goods transport instead of its applications in supply chain and material flow only. 


\section{DEFINING TRANSPORT LOGISTICS}

The term 'Transport Logistics' could be defined as 'the detailed planning, design, implementation and control of complex operations in the movement of goods or passengers'. Moreover, Transport Logistics sets it apart from other references, such as military logistics and logistics in supply chains.

A necessity for this new understanding is the future role of Transport Logistics research and study to meet the challenge of Industry 4.0 requirements, expressed as a highly integrated smart factory, in which individual goods are produced sustainably in a mass-production manner to fulfil customer demands in a global competition' [22]. Smart logistics systems' corresponding development and application employ the Internet of Things (IoT), big data, cloud computing, and Artificial Intelligence (AI). Smart transport systems use the same technologies and platforms as smart logistics systems, giving credence to developing Transport Logistics as a unified field of academic pursuit that combines the different modes of Transport to simultaneously study the movement of people and goods in a given area or period.

Therefore, unlike in the casual use of the word Logistics in industry, the term Transport Logistics in academia has potential for applications of significant complexity, where reason and solutions are derived using calculations based on logical inferences. The term Logistical Analysis, which when applied to Transport Logistics should be read as the systematic study of quantifiable measurements to determine the means of improving movement and handling of goods and people by improving the efficiency of the delivery of the respective services and increasing its value to the customer'. The corresponding functions for designing the complex multimodal networks, supporting their efficient operation and any auxiliary systems for delivery of services such as scheduling, routing, ticketing, tracking and tracing, falling within the definition of Transport Logistics Engineering, a developing new area of academic pursuit. The more traditional role of Transportation Engineering in Civil Engineering, which is the author's background, is mainly in the planning, design, construction, maintenance, and operation of physical transport infrastructures such as roads, railways, ports and airports required to move goods and passengers. However, it has expanded to include public transport services and the use of goods delivery algorithms in recent times.

Many academic programs use the word transport or transportation but predominantly study the features of only one mode of Transport, its infrastructure or its services and in some cases, both. The pull from jobs in the industry results in the demand for modespecific competencies instead of a sector-based competency. Consequently, this has 
given rise to a global phenomenon of insulated sub-sectors, agencies and even professionals competent in one mode of Transport and its development, but have not been privy to a holistic understanding of the fundamentals of mobility as the determinant of the demand for all the modes of Transport and their related Logistics as defined by the word Transport Logistics. Transport Logistics can therefore be understood as a supply-side function that facilitates the solution of a difficult or complex operational issue in transport.

\section{CONCLUSIONS}

This paper discusses the necessity to reconsider the definition and use of the words Transport and Logistics in academic instruction and scientific study as there is considerable overlap between the meanings of the two terms. The paper argues that:

(i) The role of Logistics in supply chain management is different to the role of Logistics in mobility. The latter could be more accurately defined as Transport Logistics to set it apart from Military Logistics, Logistics in Supply Chain (sometimes called Business Logistics), Service Logistics or its application in other areas.

(ii) The proposed term Transport Logistics is applied to both passenger and goods transport and not to goods only as defined by professional organisations in supply chain management and logistics.

(iii) For further clarity, the term Transport Logistics could be categorised as,

a. Goods Transport Logistics - referring to the logistical support in the movement of goods across a supply chain.

b. Passenger Transport Logistics - referring to the logistical support in the movement of people across a multimodal transport network.

(iv) Terms such as maritime logistics, railway logistics, airport logistics etc., may be used when analysing the mobility function within a single mode of transport. Transport Logistics essentially captures the complexity of multimodal operations that reflect the nature of the demand for mobility but can include these unimodal logistics functions.

(v) Moreover, the term Logistics in any of the above applications should refer to solving a complex operational problem by a rational and logical process that can be mathematically expressed. The term should not be used in academia or scientific literature for non-complex transport functions as commonly observed. 


\section{ACKNOWLEDGEMENTS}

The author acknowledges with appreciation the invitation from the Editor of the Journal of South Asian Logistics and Transport (JSALT) to submit a Strategic Perspective. The author also wishes to thank Dr Pradeepa Jayaratne and Dr Niles Perera for their valuable insights in supply chain and logistics that have vastly contributed to refining the concepts presented in this paper.

\section{REFERENCES}

[1] "Merriam-Webster Dictionary," [Online]. Available: https://www.merriamwebster.com/dictionary/transport. [Accessed 1 September 2021].

[2] "Oxford English Dictionary," 2019. [Online]. Available: https://www. oxfordlearnersdictionaries.com/definition/english/transport_1?q=transport. [Accessed 1 September 2021].

[3] Harper and R. Douglas, "Etymonline Dictionary," Oxford University Press, 2011. [Online]. Available: https://www.etymonline.com/word/transport?ref= etymonline_crossreference\#tetymonline_v_16899. [Accessed 1 September 2021].

[4] "Oxford English Dictionary," Oxford University Press, 2019. [Online]. Available: https://www.oxfordlearnersdictionaries.com/definition/english/ transportation. [Accessed 1 September 2021].

[5] "Oxford English Dictionary," Oxford University Press, 2019. [Online]. Available: https://www.oxfordlearnersdictionaries.com/definition/english/ logistics?q=logistics. [Accessed 1 September 2021].

[6] Harper and R. Douglas, "Online Etymonline Dictionary," [Online]. Available: https://www.etymonline.com/search?q=logistics. [Accessed 1 September 2021].

[7] "Merriam-Webster Dictionary," [Online]. Available: , https://www.merriamwebster.com/dictionary /logistics\#note-1. [Accessed 1 September 2021].

[8] "Oxford English Dictionary," Oxford University Press, [Online]. Available: https://www.oxfordlearnersdictionaries.com/definition/english/logistics. [Accessed 1 September 2021].

[9] "The International Society of Logistics. SOLE," [Online]. Available: http://www.sole.org/info.asp. [Accessed 14 September 2021]. 
[10] De Jomini Baron, "Tableau Analytique des principales combinaisons De La Guerre, Et De Leurs Rapports Avec La Politique Des États: Pour Servir D'Introduction Au Traité Des Grandes Opérations Militaires," 1830, p. 74.

[11] "Oxford English Dictionary," Oxford University Press, 2019. [Online]. Available: https://www.oxfordlearnersdictionaries.com/definition/english/ transportation. [Accessed 1 September 2021].

[12] NATO Standardization Agency, Glossary of Terms and Definitions - AAP 6, North Atlantic Treaty Organisation, 2013.

[13] "Council of Supply Chain Management Professionals (CSCMP)," [Online]. Available: https://cscmp.org/. [Accessed 1 September 2021].

[14] "Council of Supply Chain Management Professionals (CSCMP)," [Online]. Available: https://cscmp.org/CSCMP/Educate/SCM_Definitions_and_ Glossary_of_Terms.aspx. [Accessed 1 September 2021].

[15] Drucker and Peter F, "Big Business and Public Policy," vol. 3, no. 1, pp. 4-13, 1962.

[16] "Supply Chain and Logistics Institute," GeorgiaTech, [Online]. Available: https://www.scl.gatech.edu/resources/glossary?letter=a. [Accessed 1 September 2021].

[17] Bhasin and Hitesh, "Business Logistics - Definition and Importance," 2021. [Online]. Available: https://www.marketing91.com/ business-logistics/. [Accessed 14 September 2021].

[18] Jenkins Abby, "Logistics for Business Defined: Importance Role and Benefits," Oracle Netsuite, 2020. [Online]. Available: https://www .netsuite.com/portal/resource/articles/erp/logistics.shtml. [Accessed 14 September 2021].

[19] Schrijver A, "On the history of the transportation of and maximum flow problems," in Mathematical Programming, 2002, pp. 225-437.

[20] "Chartered Institute of Logistics and Transport UK," [Online]. Available: https://ciltuk.org.uk/Knowledge/Knowledge-Bank/Resources/OtherResources/Useful-glossaries. [Accessed 1 September 2021].

[21] Speranza M Grazia, "Trends in transportation and logistics," European Journal of Operational Research, vol. 264, no. 3, pp. 830-836, 2018. 
JSALT Volume 1 Issue 2, September 2021

[22] Winkelhaus Sven and Eric H. Gross, "A systematic review towards a new logistics system," International Journal of Production review towards a new logistic system, pp. 18-43, 2020. 